\title{
CORRECTION
}

View Article Online

View Journal I View Issue

\section{(1) Check for updates Correction: 2D oxides on metal materials: concepts, status, and perspectives}

Cite this: Phys. Chem. Chem. Phys., $2021,23,12495$

Giovanni Barcaro and Alessandro Fortunelli*

Correction for '2D oxides on metal materials: concepts, status, and perspectives' by Giovanni Barcaro et al., DOI: $10.1039 / d 1 c p 90104 d$ Phys. Chem. Chem. Phys., 2019, 21, 11510-11536, DOI: 10.1039/C9CP00972H.

rsc.li/pccp

The authors would like to correct one sentence in the Acknowledgements section of their Perspective article.

The sentence:

"A. F. gratefully acknowledges support from the QUEFORMAL FET-Open EU project." should be changed into:

"We acknowledge the funding from the European Union's Horizon 2020 research and innovation programme under grant agreement No. 829035."

The Royal Society of Chemistry apologises for these errors and any consequent inconvenience to authors and readers. 